\title{
Imaging and monitoring in minimally invasive valve surgery using an intra-aortic occlusion device: a single center experience
}

\author{
Calogera Pisano $^{1 \#}$, Andrea Farinaccio ${ }^{2 \#}$, Claudia Altieri ${ }^{1}$, Valentina Ajello ${ }^{2}$, Paolo Nardi ${ }^{1}$, \\ Dionisio Ferdinando Colella ${ }^{2 *}$, Giovanni Ruvolo ${ }^{1 *}$ \\ ${ }^{1}$ Cardiac Surgery Unit, Department of Surgical Science, Tor Vergata University Hospital, Rome, Italy; ${ }^{2}$ Cardiac and Thoracic Anesthesia Unit, Tor \\ Vergata University Hospital, Rome, Italy \\ Contributions: (I) Conception and design: C Pisano, A Farinaccio; (II) Administrative support: Ruvolo; (III) Provision of study materials or patients: C \\ Pisano, A Farinaccio; (IV) Collection and assembly of data: C Altieri, V Ajello, P Nardi; (V) Data analysis and interpretation: C Pisano, A Farinaccio; \\ (VI) Manuscript writing: All authors; (VII) Final approval of manuscript: All authors. \\ \#These authors contributed equally as first author; \\ *These authors contributed equally as last author. \\ Correspondence to: Calogera Pisano, MD, PhD. Tor Vergata University Hospital, Viale Oxford 81, 00133 Rome, Italy. Email: lindapisano82@gmail.com.
}

Background: Minimally invasive approach through a right mini-thoracotomy is a world-wide used procedure for mitral valve surgery. We performed a retrospective analysis based on our center experience in order to propose an effective, safe and reproducible method using an intra-aortic occlusion device.

Methods: This is a retrospective analysis on 48 consecutive patients undergoing mitral valve surgery through a right anterolateral mini-thoracotomy in our center. An intra-aortic occlusion device was used for aortic clamping and cardioplegia delivery. Simultaneous multi-plane three-dimensional echocardiography imaging was acquired to detect the venous cannulas position, the intra-aortic device location in the ascending aorta, the balloon inflation, the complete occlusion of the aorta, the cardioplegia delivery, the origin and the blood flow in the right coronary artery. Aortic root pressure was measured by the tip of the intraaortic occlusion device. A bilateral upper extremity invasive arterial pressure monitoring was detected. Neuromonitoring was performed through bilateral cerebral oximetry.

Results: The analysis has shown no aortic dissection, neurological damage type 1 and myocardial ischemia in the study population. In 3 cases a distal displacement of the intra-aortic occlusion device was promptly detected by the combined use of echocardiographic imaging and by a drop of the right cerebral oximetry saturation and of the right radial artery pressure.

Conclusions: The combined use of transesophageal simultaneous multi-plane three- dimensional echocardiography imaging, bilateral upper extremity invasive arterial pressure monitoring, aortic root pressure and cerebral oximetry is an effective, safe and reproducible method in patients undergoing minimally invasive valve surgery using an intra-aortic occlusion device.

Keywords: Minimally invasive approach; mitral valve surgery; three dimensional echocardiography; intra-aortic occlusion device

Submitted Oct 07, 2020. Accepted for publication Dec 17, 2020.

doi: $10.21037 /$ jtd-20-3032

View this article at: http://dx.doi.org/10.21037/jtd-20-3032

\section{Introduction}

Minimally invasive mitral valve surgery has been well established as an alternative to the conventional approach thanks to its benefits in terms of less surgical trauma, better pain control, reduced length of ICU-stay and shorter hospitalization (1-3). The surgical access is performed through a right mini-thoracotomy in the fourth intercostal 
space, which requires a peripheral cannulation in order to establish cardiopulmonary bypass (CPB) (4).

Aortic clamping in minimally invasive mitral surgery is one of the most important open discussion (5-7). Two main techniques have been described in the last few years. The first technique consists in using an external aortic clamp (EAC) (8): the clamp device is introduced through the surgical access or by performing a separate skin incision and a catheter is inserted in the aortic root to deliver cardioplegia and aortic venting.

The second technique requires an endo-aortic balloon (EAB) $(9,10)$. The EAB consists of a three-lumen catheter in which a balloon is placed at its tip; the main lumen is used for the administration of cardioplegia and for the aortic root venting; the other two lumens are for balloon inflation and deflation and for pressure monitoring. The catheter is introduced in the common femoral artery and inflated at the level of ascending aorta proximal to the innominate artery. The absence of a cardioplegia cannula in the aortic root and the opportunity of an aortic clamping with cardioplegia administration in redo cases, are important advantages of this approach.

However, the positioning of an $\mathrm{EAB}$ can have important complications such as aortic or other great vessels dissection, mobilization and embolism of atherosclerotic plaques and occlusion of innominate artery, in case of malposition or migration of the inflated balloon. For this reason, in order to avoid $\mathrm{EAB}$ malpositioning, and its subsequent dislocation, a transesophageal echocardiography (TEE) (4) monitoring is required during the insertion of the catheter and during inflation-deflation procedures. Nevertheless, the balloon migration can occur at any time during the $\mathrm{CPB}$ : an increase in the anterograde cardioplegia flow, catheter retraction and a decrease in perfusion pressure are factors that promote distal balloon migration. Moreover, an increase in perfusion pressure and strong root vent suction are related to proximal balloon dislocation. In this study we retrospectively analyzed our center experience in minimally invasive mitral valve surgery using the intra-aortic occlusion device. In particular, we described the imaging and monitoring method that was applied in all cases in order to increase the safety of the intra-aortic occlusion device and to reduce related complications. We present the following article in accordance with the STROBE reporting checklist (available at http://dx.doi.org/10.21037/jtd-20-3032).

\section{Methods}

\section{Population}

We retrospectively analyzed 48 consecutive patients who undergoing minimally invasive mitral valve surgery through a right antero-later mini-thoracotomy in our Cardiac Surgery Unit, between January 2015 and July 2018. All patients admitted for mitral valve repair or mitral valve replacement were included, even with cardiac reoperation and combined procedures (concurrent tricuspid surgery). The study was conducted in accordance with the Declaration of Helsinki (as revised in 2013) and was approved by the Institutional Ethic Board of Tor Vergata University Hospital in Rome. Individual consent for this retrospective analysis was waived.

\section{Preoperative characteristics}

All patients underwent preoperative coronary angiography, chest X-ray and full transthoracic echocardiography (iE33, Philips Medical Systems). TEE (iE33, Philips Medical Systems) was performed before the surgical procedure in case of doubts in the interpretation of transthoracic images and always after the induction of anesthesia in the operation theatre according the ASE/SCA Guidelines (11). In all the cases with a documented history or clinical suspicion of peripheral vascular disease or thoraco-abdominal aortic disease, we performed a preoperative CT scan of whole aorta. Patient's preoperative characteristics align with the definition of the EuroSCORE II model. The exclusion criteria for minimally invasive surgery using EAB: ascending aorta sinotubular junction $>35 \mathrm{~mm}$; aortic valve regurgitation $>2+$; aortic abnormality and tortuosity; severe calcification and stenosis of the femoral artery; severe aortic atherosclerosis (grade 2 to 5 according the Katz and colleagues classification) (12); right chest disease or previous right lung/pleura surgery or others potential causes of significant pleural adhesions in the right hemithorax; stroke or other neurological damage; endocarditis.

\section{Anesthesiologic management and bemodynamic monitoring}

Two cannulae for bilateral invasive monitoring of arterial pressure were placed in the right and the left radial artery.

After the general anesthesia induction, orotracheal intubation was performed with a single lumen tube through which a bronchial blocker (Cohen Endobronchial Blocker Set Cook Inc., Bloomington IN 47404, USA) has been placed under direct bronchoscopic control to perform one- lung ventilation.

A three-dimensional transesophageal probe $\mathrm{X} 7-2 \mathrm{t}$ was inserted through a laryngoscopic maneuver. 


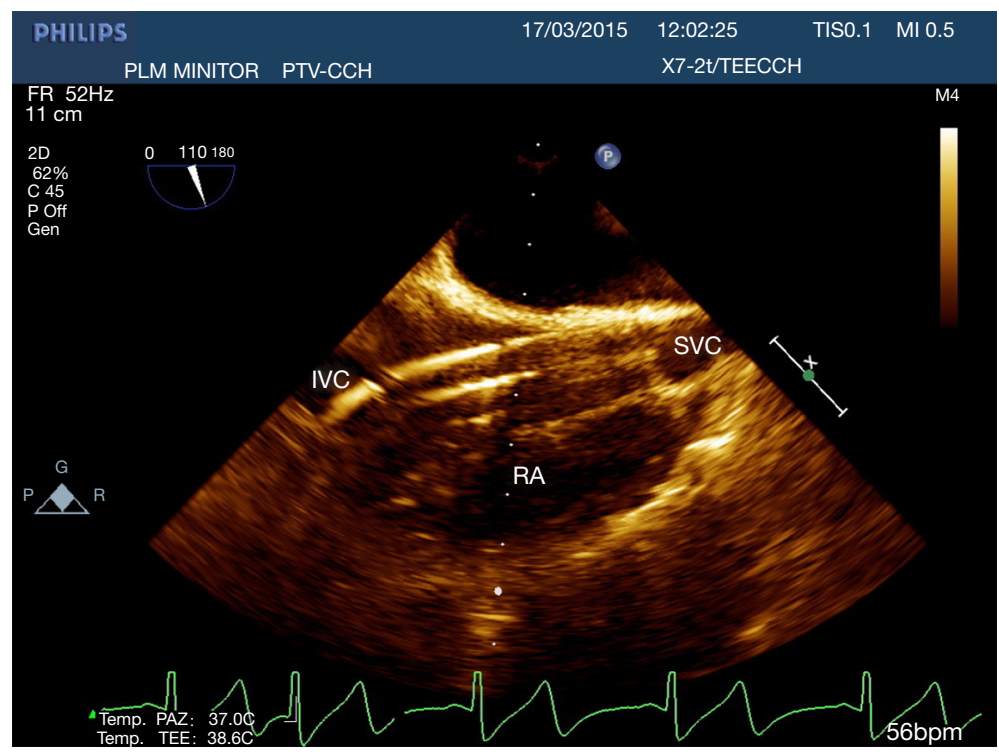

Figure 1 TEE mid-esophageal bicaval view. Two stage cannulas passing through the right atrium. TEE, transesophageal echocardiography; IVC, inferior vena cava; SVC, superior vena cava; RA, right atrium.

After the preparation of a sterile field, a central trilumen venous catheter and an upper vena cava cannula for venous drainage of the right atrium were placed in the right internal jugular vein, under L11-3 linear probe sonographic control. The correct positioning of the wires and of the cannulas was verified through transesophageal echocardiographic images.

Continuous neuromonitoring was performed through the near infrared spectroscopy (INVOS ${ }^{\mathrm{TM}}$ Cerebral/Somatic Oximeter, Somanetics Corp., Troy, MI 48083, USA) and Bispectral Index (BIS VISTA ${ }^{\mathrm{TM}}$ monitoring System, Aspect Medical Systems, Inc., Newton, MA 02464, USA).

A complete TEE examination (QLAB 10.0, cardiac 3DQ, Philips Medical Systems) was performed always by the same anesthesiologist before the onset of CPB. The mitral valve was studied through the collection of standard two-dimensional (2D) images and measurements; three-dimensional (3D) reconstruction with $3 \mathrm{D}$ zoom and full volume techniques was also collected. Multiplane Reconstruction (MPR) was used for the quantitative analysis which involves the measurement of the commissural and anterolateral diameters and the quantification of $3 \mathrm{D}$ vena contracta area and regurgitant volumes in order to grade the severity of the mitral valve disease. During the perioperative TEE in all patients we collected the following aortic key parameter: anulus, aortic root, sinutubular junction and ascending aorta were measured inner edge to leading edge in mid-esophageal long axis view. The diameter and quality of the thoracic aorta was studied through a mid-esophageal long axis and short axis view.

\section{Surgical technique}

Femoral vessels were exposed over the groin skin line with a $3-\mathrm{cm}$ incision. The femoral vein was cannulated by a twostage cannula 23/25 Fr using the Seldinger technique under TEE guidance (Figure 1, Videos 1,2). Because an EAB was used, an Edwards EndoReturn arterial cannula (21-23 Fr) was inserted in the femoral artery. Afterwards, a guidewire was introduced and advanced into the ascending aorta under TEE guidance. Once the guide-wire was properly visualized, the catheter was introduced over to reach the appropriate position in ascending aorta. The device used for endoluminal aortic clamping was the Intraclude ${ }^{\circledR}$ (Edwards Lifesciences). The EAB was finally placed over the guide-wire before CPB onset. A 5-6 cm incision was then made at the inframammary fold in female patients and through the nipple in male patients. The mini-thoracotomy was performed at the level of the 4th intercostal space. A rib spreader was used in some cases to allow a better visualization of the aorta. Two ports were placed in the 4th and 6th intercostal space for intracardiac suction line and carbon dioxide delivery. The pericardium was opened $2 \mathrm{~cm}$ above the phrenic nerve and in most cases, two retraction stitches were passed. The carbon dioxide delivering at 3-4 L/min was used for deairing. $\mathrm{CPB}$ was started and the patient cooled down $30-32{ }^{\circ} \mathrm{C}$. 

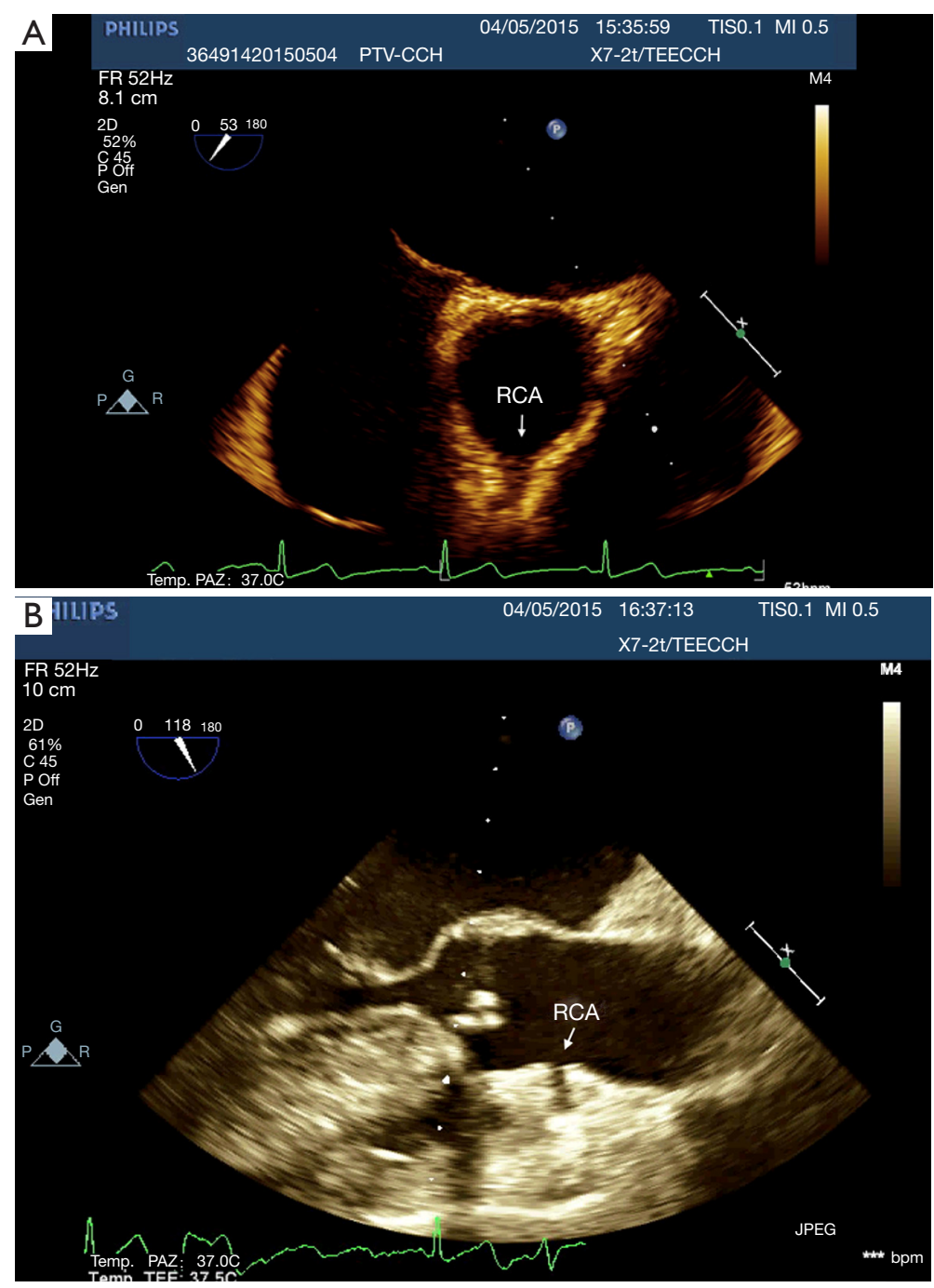

Figure 2 Transesophageal identification of the right coronary sinus. Long axis view of high right coronary artery (RCA)'s origin (A). Short axis view of the coronaries origin (B).

Vacuum-assisted venous drainage was utilized (maximum negative pressure $-40 \mathrm{mmHg}$ ). Custodiol cardioplegia has been used in all cases. The left atrium was opened at the level of the interatrial groove; an atrial retractor with a side arm was placed laterally to the mammary artery in the same intercostal space as the mini-thoracotomy. In cases of concurrent surgery, the tricuspid valve was exposed through a conventional oblique right atriotomy. All the surgical procedures have been performed by the same surgeon.

\section{Endoclamp management}

After the establishment of systemic perfusion, the EAB was inflated under continuous TEE monitoring. In order to assess the correct position of the balloon at the level of the sinotubular junction, first of all we verify the patency of the right coronary sinus (Figure 2). A Simultaneous Multiplane TEE image was then recorded to visualize at the same time the tip of the balloon (short axis view) and the position of the balloon in the ascending aorta (long axis view). Anyway, once the left atrium was opened, TEE failed to locate the $\mathrm{EAB}$ due to air interposition. After initial placement, and opening of the atrium, arterial pressure measurement of bilateral upper extremities, aortic root pressure and cerebral oximetry were used to detect possible displacement of the EAB. 
Table 1 Clinical characteristics of study population

\begin{tabular}{|c|c|}
\hline Variables & Patients $(n=48)$ \\
\hline Gender, male & $23(48 \%)$ \\
\hline Age (years) & $60 \pm 5$ \\
\hline \multicolumn{2}{|l|}{ Mitral valve disease } \\
\hline Functional disease & $36(76 \%)$ \\
\hline Rheumatic disease & $7(14 \%)$ \\
\hline Degenerative disease & $5(10 \%)$ \\
\hline \multicolumn{2}{|l|}{ Surgical procedure } \\
\hline Mitral valve repair & $35(73 \%)$ \\
\hline Mitral valve replacement & $13(27 \%)$ \\
\hline \multicolumn{2}{|l|}{ Repair techniques } \\
\hline Anuloplasty & $43(90 \%)$ \\
\hline Leaflet Resection & $26(60 \%)$ \\
\hline Neochordae implantation & $10(20 \%)$ \\
\hline Sliding plasty & $5(10 \%)$ \\
\hline Combined tricuspid repair & $7(14 \%)$ \\
\hline Mean operation time (minute) & $260 \pm 40$ \\
\hline $\begin{array}{l}\text { Mean cardiopulmonary bypass time } \\
\text { (minute) }\end{array}$ & $151 \pm 22$ \\
\hline Mean clamp time (minute) & $113 \pm 18$ \\
\hline \multicolumn{2}{|l|}{ Distal displacement of intra-aortic } \\
\hline Occlusion device & $3(2 \%)$ \\
\hline Aortic dissection & $0(0 \%)$ \\
\hline Neurological damage type I & $0(0 \%)$ \\
\hline Myocardial ischemia & $0(0 \%)$ \\
\hline \multicolumn{2}{|l|}{ Median post-operative hospital } \\
\hline Stay (day) & $7 \pm 2$ \\
\hline Freedom to operation at 2 years & $99 \% \pm 1 \%$ \\
\hline Overall survival at 2 years & $96 \% \pm 1 \%$ \\
\hline In hospital death & $0(0 \%)$ \\
\hline
\end{tabular}

\section{Postoperative characteristics and follow-up}

In order to monitor myocardial damage, cardiac enzymes (high sensibility troponin; troponin I and troponin T, myoglobin, creatine kinase $\mathrm{MB}$ ) and a 12 leads ECG were routinely evaluated after 12-18 hours since the end of the operation in postoperative day 1 and every day until postoperative day 3 .
All patients underwent chest X-rays in postoperative day 1, 2 and 4; a transthoracic echocardiography was performed for the assessment of procedure results in terms of residual pathology and effects of valve repair, or prosthetic valve function. We identified neurological damage in Type I (focal injury, or stupor or coma at discharge) and Type II (deterioration in intellectual function, memory deficit, or seizures) according to Roach et al.'s definitions (13).

Complications were recorded within 30 days since.

\section{Statistical analysis}

Continuous data are presented as mean and standard deviation, instead categorical data are expressed as percentages and absolute values. STATA 13.1 software (Stata Corp, College Station, Texas USA) was used for data analysis.

\section{Results}

Demographic and clinical results data are presented in Table 1. The mean age was $60 \pm 5.5$ years, 23 patients $(48 \%)$ were male and $25(52 \%)$ were female. The most predominant pathology was degenerative disease $(76 \%)$, followed by functional mitral valve regurgitation (14\%) and rheumatic disease (10\%). Mitral valve repair was performed in 35 cases $(73 \%)$, mitral valve replacement was performed in 13 cases $(27 \%)$. Repair techniques included: anuloplasty (90\%), leaflet resection $(60 \%)$, neochordae implantation (20\%) and sliding plasty (10\%). In 7 patients (14\%) concurrent tricuspid valve repair has been performed. In particular, three of them had severe secondary tricuspid regurgitation and four of them had moderate secondary tricuspid regurgitation with dilated annulus ( $\geq 40 \mathrm{~mm}$ or $>21 \mathrm{~mm} / \mathrm{m}^{2}$ by $2 \mathrm{D}$ echocardiography). Mean operation time, CPB and aortic clamp times were $260 \pm 40,151 \pm 22,113 \pm 18$ minutes, respectively. In 3 cases a distal displacement of the intra-aortic occlusion device was promptly detected by the combined use of echocardiographic imaging and by a drop of the right cerebral oximetry saturation and the right radial artery pressure. After the correct repositioning of the device, the operation has been performed without any complications.

Median postoperative hospital stay was $7 \pm 2$ days. No patients had incidence aortic dissection, no neurological damage type 1 and myocardial ischemia. No patients died in hospital. Freedom to operation was $98 \% \pm 1 \%$ at 2 years. Overall survival at two years was $96 \% \pm 1 \%$. 


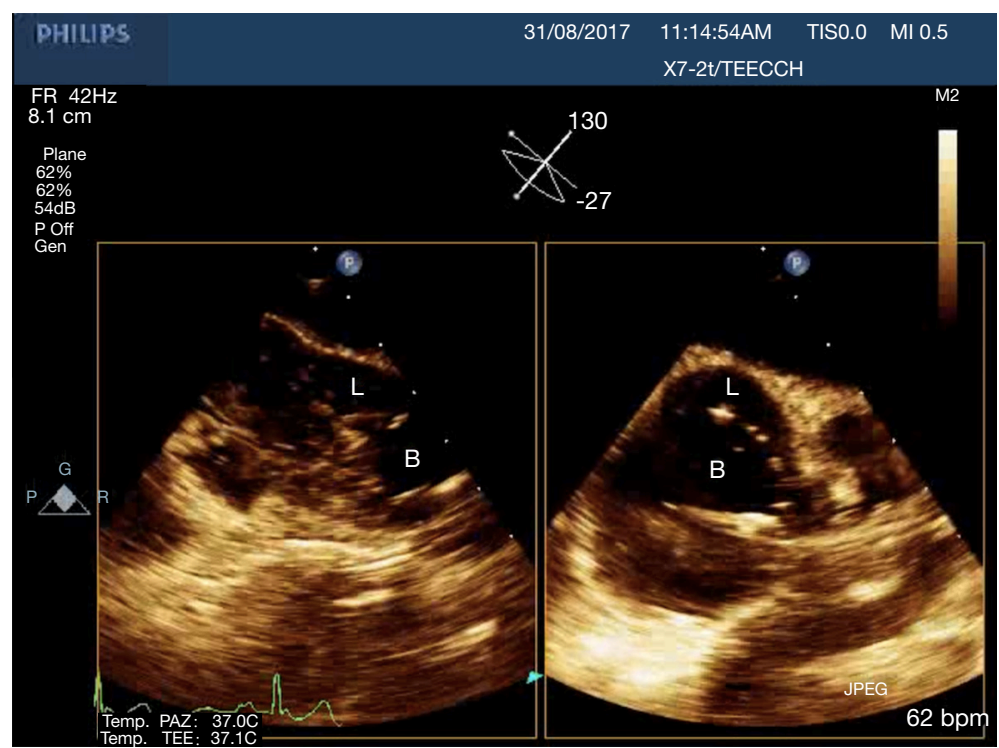

Figure 3 Simultaneous multiplane transesophageal imaging of the ascending aorta. L, lumen; B, balloon.

\section{Discussion}

In this study we described our experience in minimally invasive mitral valve surgery using the $\mathrm{EAB}$ and applying a standard method of imaging and monitoring. This method was characterized by the combined use of transesophageal simultaneous multi-plane three-dimensional echocardiography imaging, bilateral upper extremity invasive arterial pressure monitoring, aortic root pressure and cerebral oximetry. Despite several studies described an increased risk of stroke, acute iatrogenic aortic dissection and myocardial damage when the $\mathrm{EAB}$ is used in minimally invasive surgery (14-19), in our series of patients, we have not observed any of those complications. Our results are the expression of a safe and effective monitoring that allowed us an immediate diagnosis of EAB migration. As we know, motion of the balloon is a delicate balance between proximal flow either residual cardiac contraction or infusion of cardioplegia and distal flow from the proximal port of the aortic cannula. Proximal migration may prevent adequate cardioplegia or adequate aortic occlusion, as distal migration may obstruct flow to the brachiocephalic artery or even the left common carotid artery with cerebral malperfusion. For this reasons, in all our patients the positioning of the EAB device was monitored by TEE. In particular, we used the Multiplane Simultaneous TEE imaging that allowed us to verify the correct position of the $\mathrm{EAB}$ in particular in those cases in which it could not be visualized in a common
2D long axis view (Video 3). Moreover, the Simultaneous Multiplane Mode visualization of the aorta was crucial for recognizing an incomplete aortic clamping condition (Figure 3, Video 4), especially when its shape was not regular and circular (Figure 4). Anyway, once the left atrium was opened, TEE failed to locate the EAB due to air interposition. After initial placement, and opening of the atrium, arterial pressure measurement of bilateral upper extremities was used to detect possible displacement of the EAB. Finally, during the cardioplegia administration through the main lumen of the $\mathrm{EAB}$ device, we continuously monitored the bilateral radial artery pressure and aortic root pressure (Figure 5), the cerebral oximetry and the TEE images in order to early recognize a balloon distal migration. An increase in antegrade cardioplegia flow, a decrease of perfusion pressure or a catheter retraction could determine a distal displacement of the balloon (Video 5). In particular, a right drop of cerebral oximetry (Figure 6) or pressure decreasing in only the right radial artery could suggest the occlusion of the brachiocephalic trunk (Figure 7). An increase in perfusion pressure or an increase in root vent suction (Figure 8) could lead to a proximal migration of the balloon that could be promptly detected by a continuous TEE imaging of a long axis view of the aortic root and valve (Video 6).

On the other hands, the absence of iatrogenic acute aortic dissection could be related to the constant monitoring of the perfusion pressure during the operation, with particular emphasis at the beginning of $\mathrm{CPB}$ and before cross-clamping of the aorta. In addition, the femoral 


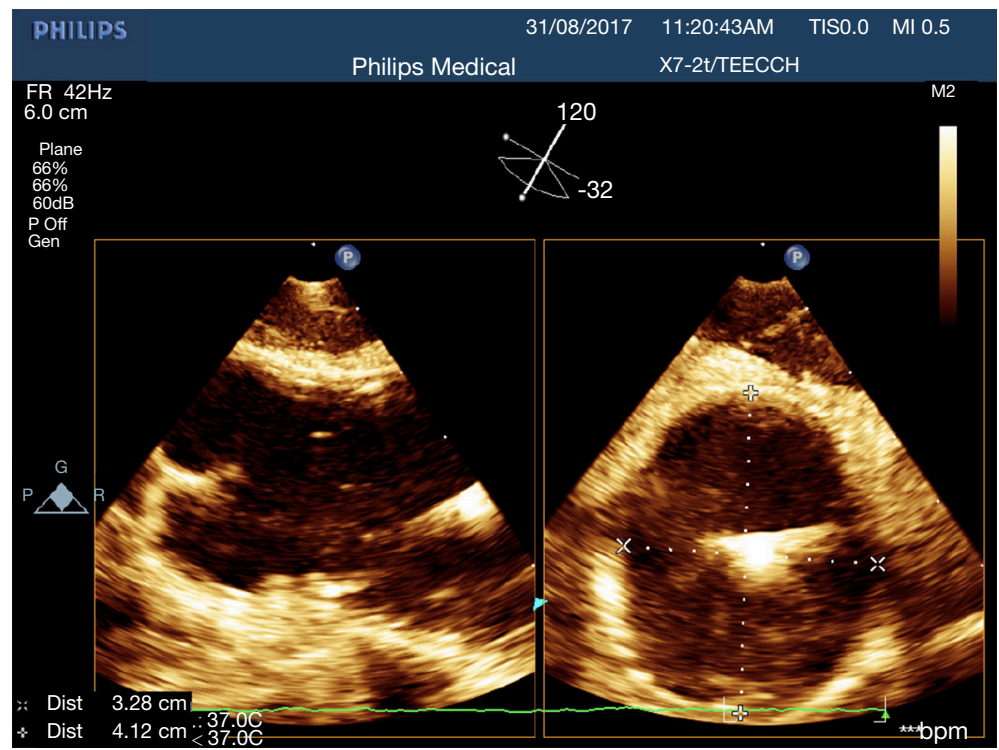

Figure 4 Simultaneous multiplane transesophageal echocardiography imaging of the ascending aorta. Long axis (A). Short axis (B). The diameters show an irregular shape of the vessel.

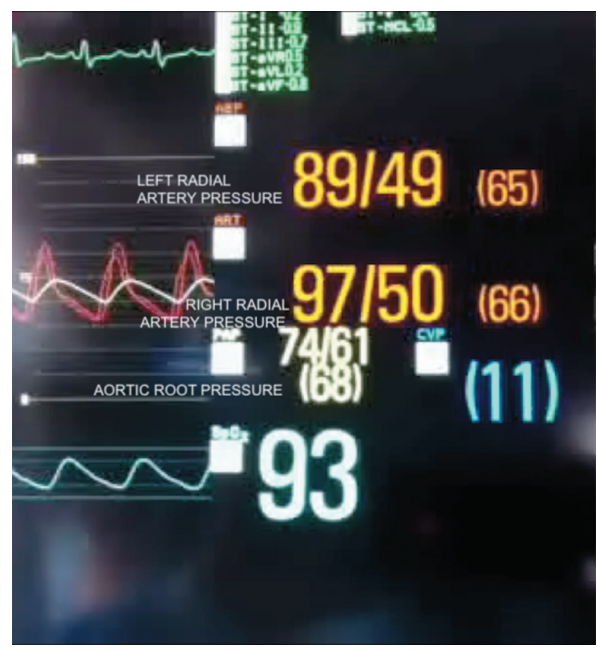

Figure 5 Hemodynamic monitoring during the procedure. Red Waves, bilateral invasive and continuous monitoring of the radial arteries. Yellow wave, aortic root pressure/Cardioplegia.

cannulation was performed in all cases using the Seldinger techniques monitored through the TEE.

Finally, despite previous evidences reported a better myocardial protection in patients operated with $\mathrm{EAC}^{5-6}$, no patients developed myocardial damage in our cases series. In our opinion, in order to prevent insufficient delivery of cardioplegia and consequent myocardial ischemia during the minimally invasive valve surgery using the $\mathrm{EAB}$, it is

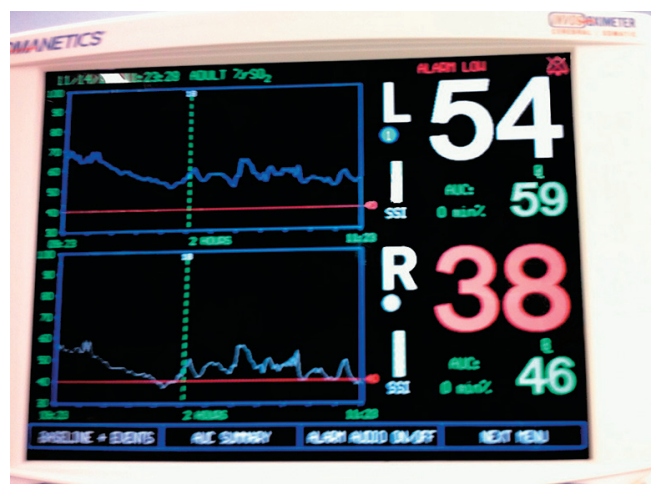

Figure 6 Right drop at the Cerebral Oximetry could indicate a distal migration of the balloon with an occlusion of the brachiocephalic trunk.

mandatory to identify the origin of both coronary arteries with the TEE. In particular we have paid attention to the right coronary flow. In fact, in most cases the right coronary artery could have an upper origin and, consequently, it could be occluded more easily by the EAB. Moreover, the visualization of the right coronary artery on TEE is usually challenging. Upper oesophagus, Mid-esophageal windows and $\mathrm{x}$-plane technique should be considered in this case. In addition, in all cases the cardioplegia pressure in aortic root was maintained above $30 \mathrm{mmHg}$ and the flow of cardioplegia was at least $250 \mathrm{~mL} / \mathrm{min}$. 


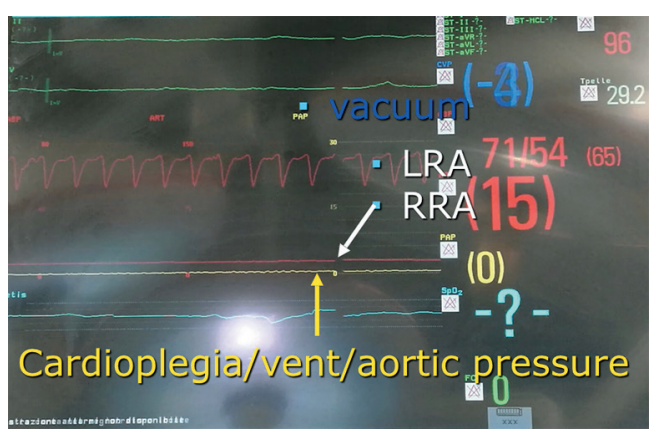

Figure 7 Distal displacement of the EAB. The occlusion of the brachiocephalic trunk determined a drop in the right radial artery pressure.

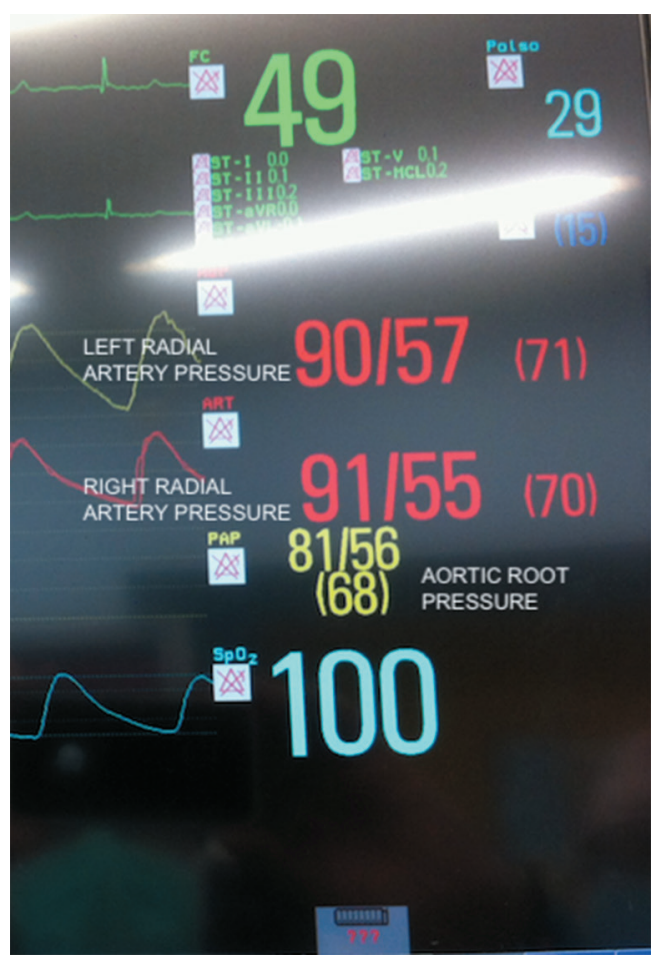

Figure 8 Identification of proximal displacement of the intraaortic occlusion device. The systemic perfusion pressure exceeds aortic root pressure.

The main limitation of the study is the small simple size. In addition this is a retrospective studies that means there may be biases in the results. Finally, this is a case-series analysis that must be verified with a randomized multicenter study in order to propose a standard protocol for the minimally invasive surgery using the intra-aortic occlusion device.

\section{Conclusions}

In our opinion, the combined use of transesophageal simultaneous multi-plane three-dimensional echocardiography imaging, bilateral upper extremity invasive arterial pressure monitoring, aortic root pressure and cerebral oximetry is an effective, safe and reproducible method in patients undergoing minimally invasive valve surgery using an intra-aortic occlusion device.

\section{Acknowledgments}

We would like to thank Professor Di Lorenzo Nicola, Director of the PHD in Medical-Surgical Sciences, Tor Vergata University, Rome.

Funding: None.

\section{Footnote}

Reporting Checklist: The authors have completed the STROBE reporting checklist. Available at http://dx.doi. org/10.21037/jtd-20-3032

Data Sharing Statement: Available at http://dx.doi. org/10.21037/jtd-20-3032

Peer Review File: Available at http://dx.doi.org/10.21037/jtd20-3032

Conflicts of Interest: All authors have completed the ICMJE uniform disclosure form (available at http://dx.doi. org/10.21037/jtd-20-3032). The authors have no conflicts of interest to declare.

Ethical Statement: The authors are accountable for all aspects of the work in ensuring that questions related to the accuracy or integrity of any part of the work are appropriately investigated and resolved. The study was conducted in accordance with the Declaration of Helsinki (as revised in 2013) and was approved by the Institutional Ethic Board of Tor Vergata University Hospital in Rome. Individual consent for this retrospective analysis was waived.

Open Access Statement: This is an Open Access article distributed in accordance with the Creative Commons Attribution-NonCommercial-NoDerivs 4.0 International License (CC BY-NC-ND 4.0), which permits the non- 
commercial replication and distribution of the article with the strict proviso that no changes or edits are made and the original work is properly cited (including links to both the formal publication through the relevant DOI and the license). See: https://creativecommons.org/licenses/by-nc-nd/4.0/.

\section{References}

1. Murphy DA, Miller JS, Langford DA, et al. Endoscopic robotic mitral valve surgery. J Thorac Cardiovasc Surg 2006;132:776-81.

2. Kara KA, Caner T. Comparison of pain in the early postoperative period using VAS score in patients after cardiac surgery who had minimally invasive incisions vs. full median sternotomy. Ann Ital Chir 2019;90:3-9.

3. Casselman FP, Van Slycke S, Wellens F, et al. Mitral valve surgery can now routinely be performed endoscop- ically. Circulation 2003;108:II48-54.

4. Irace FG, Rose D, D'Ascoli R, et al. Video assistance in mitral surgery: reaching the "Thru" port access. J Vis Surg 2015;1:13.

5. Bentala M, Heuts S, Vos R, et al. Comparing the endoaortic balloon and the external aortic clamp in minimally invasive mitral valve surgery. Interact CardioVasc Thorac Surg 2015;21:359-65.

6. Ius F, Mazzaro E, Tursi V, et al. Clinical re- sults of minimally invasive mitral valve surgery: endoaortic clamp versus external aortic clamp techniques. Innovations (Phila) 2009;4:311-18.

7. Reichenspurner H, Detter C, Deuse T, et al. Video and robotic-assisted minimally invasive mitral valve surgery: a comparison of the Port-Access and transthoracic clamp techniques. Ann Thorac Surg 2005;79:485-90

8. Chitwood WR Jr, Elbeery JR, Moran JF. Minimally invasive mitral valve repair using transthoracic aortic occlusion. Ann Thorac Surg 1997;63:1477-9.

9. Casselman F, Aramendi J, Bentala M, et al. Endoaortic Clamping Does Not Increase the Risk of Stroke in Minimal Access Mitral Valve Surgery: A Multicenter Experience. Ann Thorac Surg 2015;100:1334-9.

10. Greco E, Zaballos JM, Alvarez L, et al. Video-assisted mitral surgery through a micro-access: a safe and reliable reality in the current era. J Heart Valve Dis 2008; 17:48-53.

11. Hahn RT, Abraham T, Adams MS, et al. Guidelines for performing a comprehensive transesophageal echocardiographic examination: recommendations from the American Society of Echocardiography and the Society of Cardiovascular Anesthesiologists. J Am Soc Echocardiogr 2013;26:921-64.

12. Katz ES, Tunick PA, Rusinek H, et al. Protruding aortic atheromas predict stroke in elderly patients undergoing cardiopulmonary bypass: experience with intraoperative transesophageal echocardiography. J Am Coll Cardiol 1992;20:70-7.

13. Roach GW, Kanchuger M, Mangano CM, et al. Adverse cerebral outcomes after coronary bypass surgery. Multicenter Study of Perioperative Ischemia Research Group and the Ischemia Research and Education Foundation Investigators. N Engl J Med 1996;335:1857-63.

14. Malvindi PG, Margari V, Mastro F, et al. External aortic cross-clamping and endoaortic balloon occlusion in minimally invasive mitral valve surgery. Ann Cardiothorac Surg 2018;7:748-754.

15. Mazine A, Pellerin M, Lebon JS, et al. Minimally invasive mitral valve surgery: influence of aortic clamping technique on early outcomes. Ann Thorac Surg 2013;96:2116-22.

16. Khan H, Hadjittofi C, Uzzaman M, et al. External aortic clamping versus endoaortic balloon occlusion in minimally invasive cardiac surgery: a systematic review and meta-analysis. Interact Cardiovasc Thorac Surg 2018;27:208-214

17. Kowalewski M, Malvindi PG, Suwalski P, et al. Clinical Safety and Effectiveness of Endoaortic as Compared to Transthoracic Clamp for Small Thoracotomy Mitral Valve Surgery: Meta-Analysis of Observational Studies. Ann Thorac Surg 2017;103:676-86

18. Sündermann SH, Sromicki J, Rodriguez Cetina Biefer H, et al. Mitral valve surgery: right lateral minithoracotomy or sternotomy? A systematic review and meta-analysis. J Thorac Cardiovasc Surg 2014;148:1989-95.e4.

19. Cheng DC, Martin J, Lal A, et al. Minimally invasive versus conventional open mitral valve surgery: a metaanalysis and systematic review. Innovations (Phila) 2011;6:84-103.

Cite this article as: Pisano C, Farinaccio A, Altieri C, Ajello V, Nardi P, Colella DF, Ruvolo G. Imaging and monitoring in minimally invasive valve surgery using an intra-aortic occlusion device: a single center experience. J Thorac Dis 2021;13(2):10111019. doi: $10.21037 /$ jtd-20-3032 